TMS-2019 Shape Casting: $7^{\text {th }}$ International Symposium celebrating Prof. John Campbell's 80 th Birthday

\title{
Effect of Fe-Rich Intermetallics on Tensile Behavior of Al-Cu 206 Cast Alloys at Solid and Near-Solid States
}

\author{
K. Liu*1, X. Cao ${ }^{1,2}$, A. Bolouri ${ }^{3}$ and X.-G. Chen ${ }^{1}$ \\ ${ }^{1}$ Department of Applied Science, University of Quebec at Chicoutimi, Chicoutimi, QC, Canada, G7H 2B1 \\ ${ }^{2}$ Aerosapce Manufacturing Technology Center, National Research Council Canada, Montreal, QC, Canada, H3T 2B2 \\ ${ }^{3}$ Department of Engineering Design and Mathematics, University of the West of England, Bristol, UK, BS16 1QY,
}

\begin{abstract}
Iron is one of the most common impurity elements in $\mathrm{Al}-\mathrm{Cu} 206$ cast alloys as it often causes the precipitation of Fe-rich intermetallic phases during solidification due to its extremely low solid solubility in aluminum. The characteristics of the Fe-rich intermetallics, such as type, morphology, size, and distribution, have significant influences on the tensile behaviors of the $\mathrm{Al}$ alloys. In the present work, two $\mathrm{Al}-\mathrm{Cu} 206$ cast alloys containing different types of Fe-rich intermetallics (dominated by either platelet $\beta-\mathrm{Fe}$ or Chinese script $\alpha-\mathrm{Fe}$ ) were cast and their tensile tests were performed at both solid (room temperature) and near-solid ( 2.8 vol. \% liquid) states. It is found that the tensile properties in both solid and near-solid states are improved when the Fe-rich intermetallics change from platelet to Chinese script morphologies. During the solid state tensile deformation, the failure occurs mainly along the platelet $\beta$-Fe intermetallics/Al matrix interface or within the Chinese script $\alpha$-Fe particles. In the near-solid state, the alloy containing mainly Chinese script $\alpha$-Fe is found to have more free flow paths for liquid feeding, leading to improved tensile properties. By contrast, the platelet $\beta$-Fe can cause the blockage of the liquid flow paths, leading to the degraded tensile properties and worsened susceptibility to hot tearing.
\end{abstract}

Keywords: Al-Cu alloy; Fe-rich intermetallics; Tensile properties; Solid and near-solid state; Hot tearing.

\section{Introduction}

$\mathrm{Al}-\mathrm{Cu} 206$ cast alloys have been widely used in modern aerospace and automobile industries due to their excellent mechanical properties including elevated-temperature tensile strength. In these alloys, however, iron is considered to be one of the most common impurities and thus an extremely low upper limit for $\mathrm{Fe}$ is usually allowed, e.g. 0.15 wt. \% for 206.0 or even 0.07 wt. \% for A206.0 alloys [1] (all alloy compositions are in weight percent unless indicated otherwise). This has significantly increased the manufacturing costs and severely limited their wide applications. To this end, it is important to understand the role of Fe to increase the allowable upper limit of Fe in these alloys.

Due to the low solubility of $\mathrm{Fe}$ in solid aluminum, most $\mathrm{Fe}$ will precipitate as the $\mathrm{Fe}$-rich intermetallics during the solidification. Recently, various Fe-rich intermetallics have been reported in Al-Cu 206 cast alloys at high Fe contents [1-4]. These Fe-rich phases include platelet $\beta-\mathrm{Al}_{7} \mathrm{Cu}_{2} \mathrm{Fe}$ and $\mathrm{Al}_{3} \mathrm{Fe}$ as well as Chinese script $\alpha-\mathrm{Al}_{15}(\mathrm{FeMn})_{3}(\mathrm{SiCu})_{2}, \mathrm{Al}_{\mathrm{m}} \mathrm{Fe}$ and $\mathrm{Al}_{6} \mathrm{Fe}$ over the $\mathrm{Fe}$ levels of $0.3-0.5 \%[1,2,4]$. It is well accepted that the platelet Fe-rich intermetallics are detrimental to the mechanical properties of $\mathrm{Al}$ cast alloys due to the fact that they can act as the stress risers and crack initiators [5]. Therefore, they are usually required to be transferred into the less-harmful Chinese script Fe-rich intermetallics through controlling the 
chemical composition and solidification condition [1, 5-7]. In addition, Al-Cu 206 cast alloys are susceptible to the hot-tearing defect during solidification, which is closely related to the tensile stress arising from the thermal gradient and contraction during solidification [8,9]. It is reported that the Fe-rich intermetallics can significantly influence the hot-tearing susceptibility [10]. For example, Chinese script $\alpha$-Fe can improve the hot-tearing resistance, but the reason is not clear. Recently, the near-solid tensile testing method has been well developed to simulate the stress-strain conditions during solidification of aluminum alloys [11, 12], providing a practical approach to investigate the influence of Fe-rich intermetallics on the hot-tearing susceptibility.

In the present work, two $\mathrm{Al}-\mathrm{Cu} 206$ cast alloys with a high Fe content $(0.3 \%)$ and different $\mathrm{Mn}$ and $\mathrm{Si}$ concentrations were specially designed to obtain dominantly either platelet $\beta$-Fe or Chinese script $\alpha$-Fe intermetallic phases. The tensile tests were then performed at solid state (room temperature) and near-solid state (with a liquid volume of 2.8 vol. \%). The microstructures and the fracture surfaces of the failed tensile samples were fully analyzed to disclose the role of Fe-rich intermetallics during tensile deformation at both the solid and near-solid states.

\section{Experimental}

As indicated in Table 1, two Al-Cu 206 cast alloys with different dominant Fe-rich intermetallic phases were prepared in the present work. Alloy 311 was designed with dominant platelet $\beta$ - $\mathrm{Fe}\left(\mathrm{Al}_{7} \mathrm{Cu}_{2} \mathrm{Fe}\right)$ while Alloy 333 had mainly Chinese script $\alpha-\mathrm{Fe}\left(\mathrm{Al}_{15}(\mathrm{FeMn})_{3}(\mathrm{SiCu})_{2}\right)$. The casting parameters and process can be found in literature [1].

Table 1 Chemical composition of the experimental alloys

\begin{tabular}{cccccccc}
\hline \multirow{2}{*}{ Alloys \# } & \multicolumn{5}{c}{ Elements (wt. \%) } & \multicolumn{2}{c}{ Temperatures } \\
& $\mathrm{Cu}$ & $\mathrm{Mg}$ & $\mathrm{Fe}$ & $\mathrm{Mn}$ & $\mathrm{Si}$ & $\mathrm{Al}$ & at 2.8 vol.\% liquid* \\
\hline 311 & 4.66 & 0.27 & 0.30 & 0.12 & 0.19 & Bal. & $551^{\circ} \mathrm{C}$ \\
333 & 4.62 & 0.28 & 0.29 & 0.29 & 0.33 & Bal. & $541^{\circ} \mathrm{C}$ \\
\hline
\end{tabular}

* The temperature at a liquid volume of $2.8 \%$ was obtained from the Differential Scanning Calorimeter (DSC) curves. More experimental details can be found in the literature [11].

For the room temperature (RT) solid-state tensile testing specimens, the traditional $\mathrm{T} 7$ temper (solution treatment: $505^{\circ} \mathrm{C}$ for 2 hours $+520^{\circ} \mathrm{C}$ for 8 hours and artificial aging: $185^{\circ} \mathrm{C}$ for 5 hours) was applied. After the T7 treatment, these samples were machined to the shape and dimensions as indicated in Fig. 1a. The tensile testing was then performed at room temperature at a strain rate of $10^{-3} \mathrm{~s}^{-1}$ using an INSTRON 8801 testing system. During the tensile testing, an extensometer with a gauge length of $25 \mathrm{~mm}$ was attached to the tensile sample to record the displacement. The tensile properties, namely, ultimate tensile strength (UTS), yield strength (YS) at $0.2 \%$ offset strain, and elongation (El) were obtained from the averaged value of 3 tensile tests.

The near-solid tensile testing was performed on a Gleeble 3800 thermomechanical testing unit using the samples machined from as-cast condition with the rod-shape and dimensions shown in Fig. 1b. The testing temperatures for Alloys 311 and 333 with 2.8 vol. \% liquid are $551^{\circ} \mathrm{C}$ and $541^{\circ} \mathrm{C}$, respectively (Table 1). The temperature was monitored by using three K-type thermocouples which were spot-welded on the surface at the middle and at two sides with a distance of $\pm 8 \mathrm{~mm}$ from the middle (Fig. 1b). A ceramic tube was adopted to homogenize the temperature in the hot middle zone of the test 
sample. The tensile testing was performed at a strain rate of $10^{-3} \mathrm{~s}^{-1}$ and a minimum of 3 samples were tested. Details about the near-solid tensile testing can be found in [11].

The microstructures in the as-cast and tempered conditions as well as the fracture surfaces of the failed tensile specimens were analyzed using a Scanning Electron Microscope (SEM, JSM-6480LV). The volume percent of the iron-rich intermetallics was measured using an Optical Microscope (OM, Nikon Eclipse ME 600) equipped with an image analyzer.
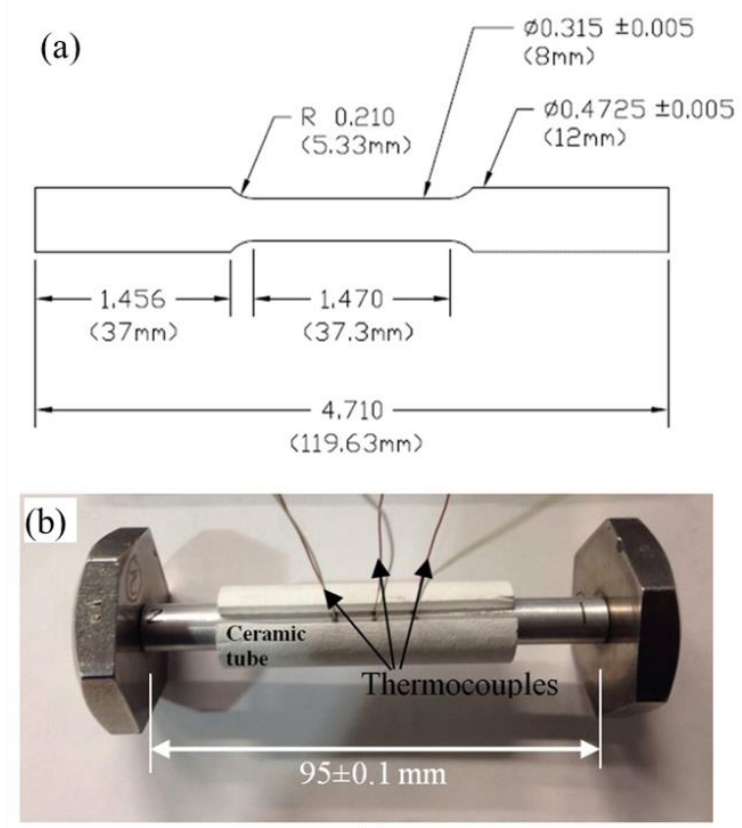

Fig. 1 Shape and dimensions of the tensile samples tested at RT (solid state) (a) and near-solid (b) state (units in inches and millimeters)

\section{Results and discussion}

Fe-rich intermetallics in as-cast and T7 heat treated conditions

Fig. 2 shows the microstructures of the two experimental alloys in the as-cast and $\mathrm{T} 7$ heat treated conditions. In addition to $\mathrm{Al}_{2} \mathrm{Cu}$ phase, the two as-cast alloys contain different dominant Fe-rich intermetallics, i.e. platelet-like $\beta$ - $\mathrm{Fe}\left(\mathrm{Al}_{7} \mathrm{Cu}_{2} \mathrm{Fe}\right)$ for Alloy 311 (Fig. 2a) and Chinese script $\alpha-\mathrm{Fe}\left(\mathrm{Al}_{15}(\mathrm{FeMn})_{3}(\mathrm{SiCu})_{2}\right)$ for Alloy 333 (Fig. 2b), which can be attributed to the higher $\mathrm{Mn}$ and $\mathrm{Si}$ contents in Alloy 333 than those in Alloy 311 [1,3]. The area percentage of the dominant Fe-rich intermetallics measured from the test-bar surface is 1.1 vol. \% for $\beta$-Fe in Alloy 311 and 1.4 vol. \% for $\alpha$-Fe in Alloy 333, respectively. Besides, it is also found that most platelet $\beta-\mathrm{Fe}$ is interlocked with $\mathrm{Al}_{2} \mathrm{Cu}$ phase while Chinese script $\alpha$-Fe is distributed in the matrix with little mutual mixture between the $\alpha-\mathrm{Fe}$ and $\mathrm{Al}_{2} \mathrm{Cu}$. This can be attributed to their different precipitation temperatures and reactions. It is reported [1] that the precipitation temperature of $\beta$ - $\mathrm{Fe}\left(\sim 570^{\circ} \mathrm{C}\right)$ is slightly higher than that of $\mathrm{Al}_{2} \mathrm{Cu}\left(\sim 540^{\circ} \mathrm{C}\right)$, explaining the mutual interlock between the two phases. In contrast, the precipitation temperature of $\alpha$ - $\mathrm{Fe}\left(\sim 625^{\circ} \mathrm{C}\right)$ is much higher than those of $\beta$-Fe $\left(\sim 570^{\circ} \mathrm{C}\right)$ and $\mathrm{Al}_{2} \mathrm{Cu}\left(\sim 540^{\circ} \mathrm{C}\right)$. Therefore, during solidification, the $\alpha-\mathrm{Fe}$ is formed prior to the $\beta$ - $\mathrm{Fe}$ and $\mathrm{Al}_{2} \mathrm{Cu}$ phases and can randomly distribute within the matrix including the interdendritic regions. 
In the $\mathrm{T} 7$ heat treated condition, almost all the $\mathrm{Al}_{2} \mathrm{Cu}$ phase was dissolved into the matrix but little change occurred for both Fe-rich intermetallics. Similarly to the as-cast condition, only platelet $\beta$-Fe and Chinese script $\alpha$-Fe phases are present in tempered Alloy 311 (Fig. 2c) and Alloy 333 (Fig. 2d), respectively.
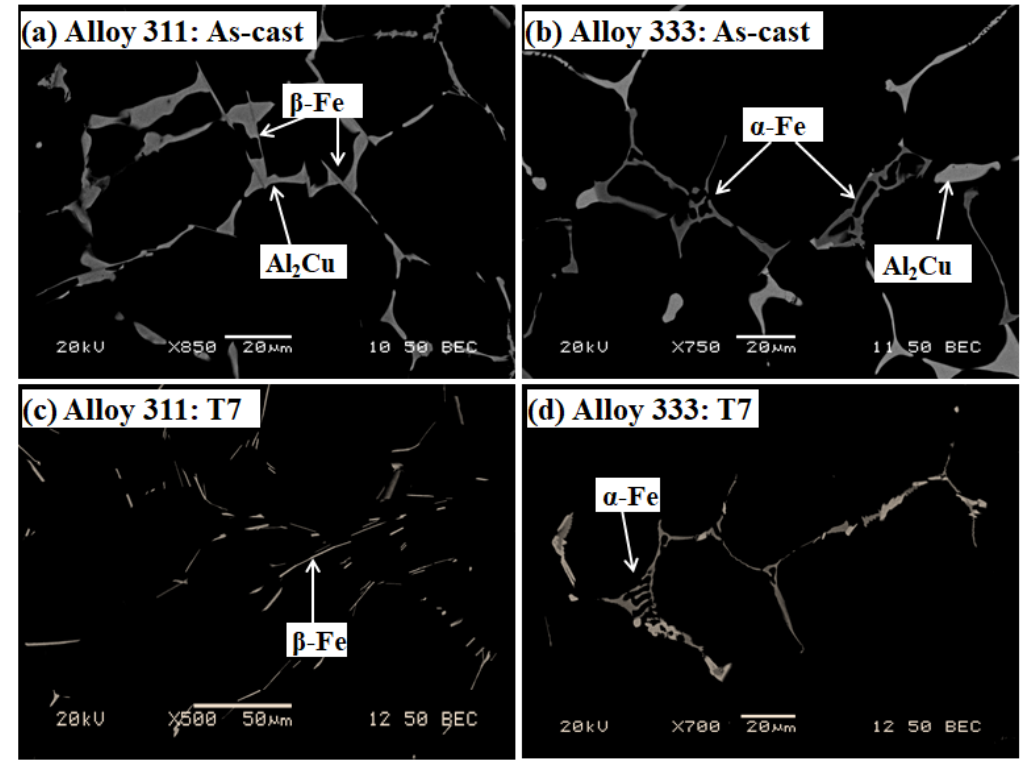

Fig. 2 Microstructure of the two experimental alloys in as-cast (a-b) and T7 (c-d) conditions

\section{$\underline{\text { Solid-state tensile behavior }}$}

Fig. 3 shows the typical engineering stress-strain curves of the two experimental alloys obtained at RT (solid state). The UTS, YS and El for Alloy 333 are $470 \mathrm{MPa}, 426 \mathrm{MPa}$ and 3.6\% compared with $425 \mathrm{MPa}, 403 \mathrm{MPa}$ and 1.2\% for Alloy 311, respectively. Therefore, all tensile properties (UTS, YS, El) are improved for Alloy 333 compared to Alloy 311, indicating that the Chinese script $\alpha$-Fe has a less harmful influence on the tensile properties than the platelet $\beta$-Fe.

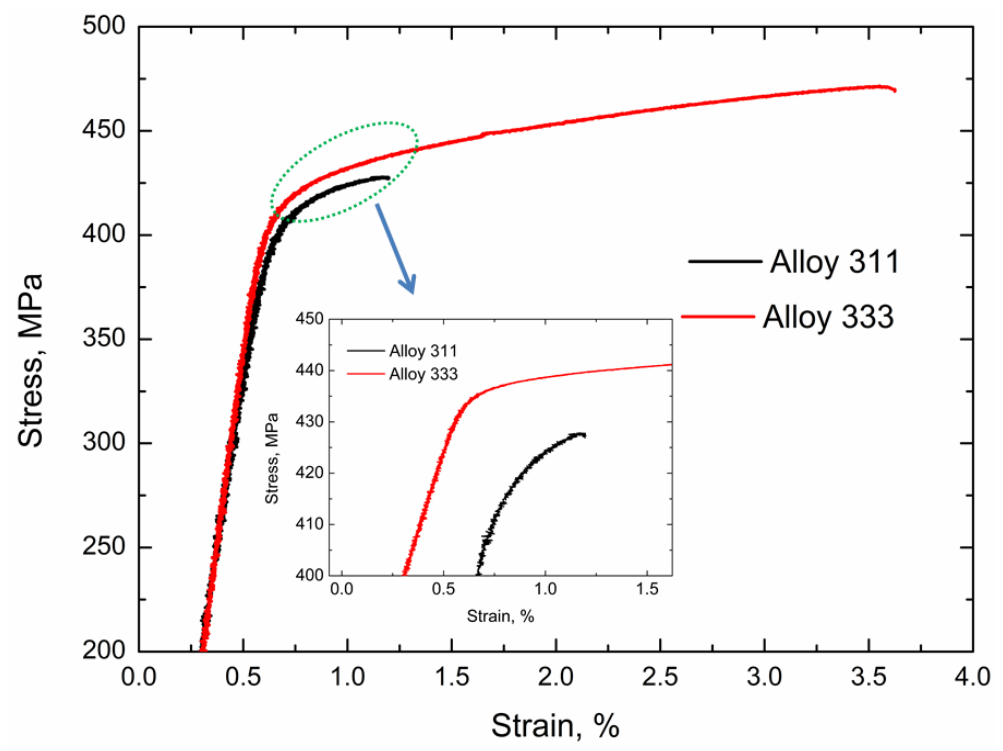

Fig. 3 Typical engineering stress-strain tensile curves for Alloys 311 and 333 tested at RT (solid state)

Fig. 4 shows the fracture surfaces of the two experimental alloys and the distribution of the Fe-rich intermetallics on the mating fracture surfaces. More brittle fracture surface is observed for Alloy 311 (Fig. 4a) while mixed (both brittle and ductile) fracture is characterized for Alloy 333 (Fig. 4b). Fig. 4c-4f shows the distribution of Fe-rich intermetallics on the 
mating fracture surfaces. The two $\beta$-Fe platelets (A in Fig. 4c and B' in Fig. 4d) are clearly observed on one side of the fracture surfaces but only the matrix is exposed on the corresponding side of the mating surfaces (A' in Fig. 4d and B in Fig. $4 \mathrm{c}$ ), indicating that the tensile cracking occurred mainly at the $\beta$-Fe platelet/Al matrix interfaces due to the nucleation of the $\beta$-Fe on one side of the oxide bifilm, or debonding/decohension between the particles and matrix. Therefore, the tensile cracking can easily initiate and propagate along the longitudinal interfaces between the $\beta$-Fe plates and $\mathrm{Al}$ matrix, leading to the brittle fracture as shown in Fig. 4a.
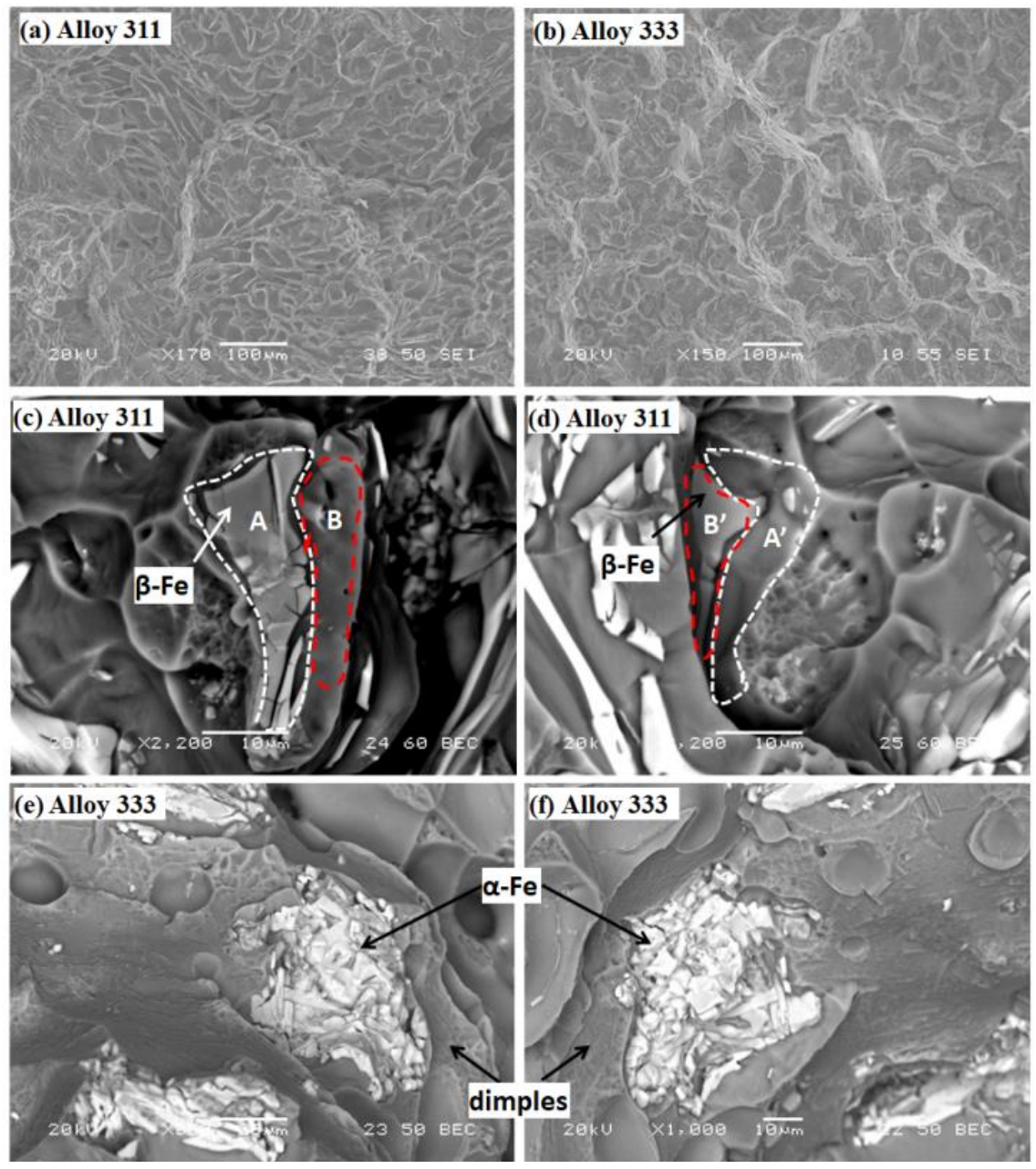

Fig. 4 Fracture surfaces of the experimental alloys (a-b) and distribution of Fe-rich intermetallics on the mating fractures (c-f)

By contrast, the distribution of Chinese script $\alpha$-Fe on the fracture surface in Alloy 333 behaves differently from the $\beta$-Fe. As shown in Fig. 4e-4f, the $\alpha$-Fe particles are observed on the corresponding locations of both mating fracture surfaces, indicating that the tensile cracking appears mainly within the particles themselves. Meanwhile, some small dimples are observed in the neighborhood of the $\alpha$-Fe particles (Fig. 4e and 4f), indicating the ductile nature of the Al matrix fracture. As mentioned in the literature [1], the $\alpha$-Fe precipitates are at relatively high temperature during solidification and thus can grow from their parent nucleus into well-developed branches/dendrites in different directions. These dendrites are mutually interwoven with the Al matrix, making the crack difficult to propagate only along the particle/matrix interfaces. Fracture within the $\alpha$-Fe particles leads to the premature failure but microvoids cannot easily develop around these large intermetallic particles. By contrast, the Al matrix can be deformed under a tensile stress, leading to the formation of some fine dimples (Fig. 4e-4f). Therefore, both brittle (for intermetallics) and ductile (for matrix) fractures appear in Alloy 333 (Fig. 4b). 
The typical stress-displacement curves for Alloys 311 and 333 tested at the near-solid state with 2.8 vol. \% liquid are shown in Fig. 5. Compared with the tensile behavior at solid state shown in Fig. 2, the difference between the two experimental alloys appears even at the very beginning of the tensile testing. As shown in Fig. 5a, the tensile stress increases more slowly with the displacement for Alloy 333 than Alloy 311 as indicated by the lower slope of the stress-displacement curve for Alloy 333. In other words, Alloy 333 can tolerate larger displacement than Alloy 311 when the same stress was applied. Since the initiation and propagation of hot cracks during casting generally occurs before the maximum stress [13] , it is reasonable to assume that expansion of damage in the mush zone takes place more slowly for Alloy 333 than that for Alloy 311, suggesting the lower hot-tearing susceptibility for Alloy 333. This observation is in good accordance with the fact that Chinese script $\alpha$-Fe can improve the hot-tearing resistance compared to the platelet $\beta$-Fe in 206 cast alloys [10].
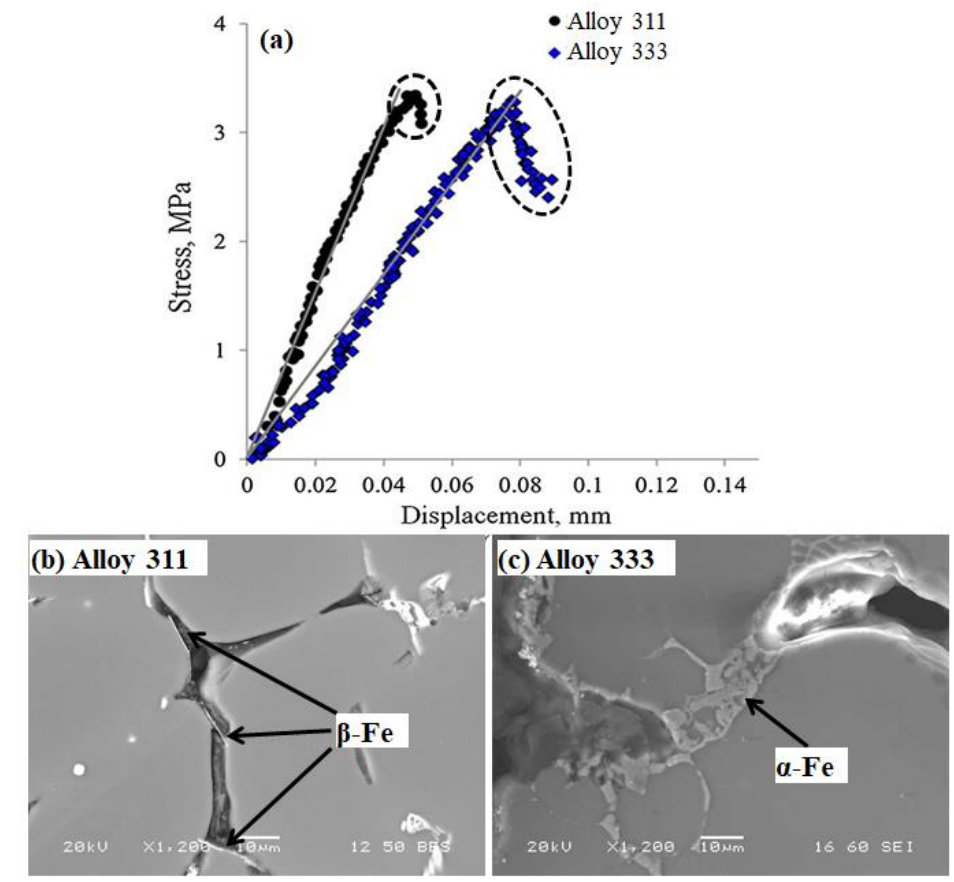

Fig. 5 Near-solid stress-displacement curves (a) and Fe-rich intermetallics along the tensile cracks close to the "near-fracture" locations for Alloy 311 (b) and Alloy 333 (c)

It is also interesting to note that more displacement to fracture appeared for Alloy 333 than that for Alloy 311 after the peak stress (marked as black-circles in Fig. 5a). Over this stage, after the peak stress but prior to the full failure, additional interrupted tensile testing was performed and metallographic specimens adjacent to the "near-fracture" location were taken to disclose the distributions of intermetallic particles along tensile cracks (Fig. 5b and 5c for Alloys 311 and 333, respectively). It was found that the cracking paths are dominantly along the $\beta$-Fe platelets (Fig. 5b), leading to an easier premature failure (i.e. shorter displacement) for Alloy 311. By contrast, the propagation of the crack can be blocked by the Chinese script $\alpha$-Fe particles (Fig. 5c), leading to delayed failure and longer displacement for Alloy 333. Therefore, Alloy 333 experienced longer displacement before the final fracture after the peak stress, as indicated in Fig. 5a. However, it is found that the peak tensile stresses are similar for both experimental alloys (3.3 MPa for Alloy 311 and 3.4 MPa for Alloy 333), which can be attributed to the same large amount of liquid ( $2.8 \mathrm{vol} . \%)$ during the tensile deformation. In this case, the liquid can completely wet the solid grains, separating them with liquid films and thus the tensile stress is mainly controlled by the liquid phase [14].

Furthermore, the total displacement to the failure is doubled for Alloy $333(0.09 \mathrm{~mm})$, as compared with Alloy 311 $(0.045 \mathrm{~mm})$, which most likely resulted from the different dominant Fe-rich intermetallics. It was reported that the feeding of liquid, especially for the last liquid phase $(<5$ vol. \%) within the mush structure determines the tensile strength of the semi-solid castings $[14,15]$. If the liquid can easily flow within the mush structure and feed the regions which are being 
tensile deformed, the structure can accommodate more deformation until the fracture failure [12]. Therefore, the significant difference in displacement for the two experimental alloys is also expected to be related to the variations in the flow of liquid during deformation caused by the different intermetallic compounds present in experimental alloys. As shown in Fig. 6, both the morphology and distribution of the Fe-rich intermetallics are found to have significant influence on the flow of the liquid during tensile deformation. In the two experimental 206 alloys, the remained liquid phase is mainly low melting point $\mathrm{Al}-\mathrm{Al}_{2} \mathrm{Cu}$ eutectic in the interdendritic regions [1]. As expected, the re-solidified $\mathrm{Al}_{2} \mathrm{Cu}$ after the near-solid tensile testing can be well observed on the fracture surfaces (Fig. 6). For Alloy 311, the re-solidified $\mathrm{Al}_{2} \mathrm{Cu}$ is present mostly in the area near or even between the $\beta$-Fe platelets (red circle in Fig. 6a). This observation has been further supported by the phenomenon that platelet $\beta$-Fe tends to be always interlocked with $\mathrm{Al}_{2} \mathrm{Cu}$ due to their similar precipitation temperatures (Fig. 2a). Therefore, the $\beta$-Fe multi-platelets present in a bundle within the interdendritic channels can block the flow of the $\mathrm{Al}_{-} \mathrm{Al}_{2} \mathrm{Cu}$ eutectic liquid and make it difficult for the remained liquid to feed the required regions during tensile deformation. In this case, the permeability of the mush structure is greatly reduced and the void/crack can easily form and propagate, explaining the faster rise and steeper slope for the stress-displacement curve and lower displacement for Alloy 311 (Fig. 5a). By contrast, the re-solidified $\mathrm{Al}_{2} \mathrm{Cu}$ is not necessary to be co-existed with the $\alpha-\mathrm{Fe}$ in the interdendritic regions for Alloy 333 (red circles in Fig. 6b), indicating the more free flow of the $\mathrm{Al}_{-} \mathrm{Al}_{2} \mathrm{Cu}$ eutectic liquid during the tensile deformation. Due to the fact that the $\alpha$-Fe is not necessarily located within the interdendritic channels as it precipitates at a much higher temperature than $\mathrm{Al}_{2} \mathrm{Cu}[1]$ and its compact morphology, the $\alpha$-Fe has less blocking effect on the flow of the remained $\mathrm{Al}_{-} \mathrm{Al}_{2} \mathrm{Cu}$ liquid compared to the platelet-like $\beta$-Fe. Therefore, the liquid can flow more freely and feed within the mush zone structure before it is fully blocked and thus accommodate a higher deformation before the final fracture, explaining the larger displacement and lower hot-tearing susceptibility for Alloy 333. Regarding to the casting of Al-Cu 206 alloys, the increase of the liquid feeding ability during the last stage of the solidification can have beneficial effect on the crack healing process, reducing additionally the hot-tearing susceptibility.


Fig. 6 Fracture surfaces after the completion of the near-solid tensile testing of the experimental alloys

\section{Conclusions}

- During the solid-state tensile testing at room temperature, tensile failure mainly occurs at the $\beta$-Fe/ $\mathrm{Al}$ matrix interfaces but within the $\alpha$-Fe intermetallic particles. Therefore, the cracking is easier to initiate and propagate along the longitudinal axial direction of the $\beta$-Fe platelets but more difficult within the $\alpha$-Fe particles, leading to the improved strength and ductility for the alloy with dominant Chinese script $\alpha$-Fe compared to that with platelet $\beta$-Fe.

- During the near-solid tensile deformation, the tensile stress increases with displacement much more slowly for the alloy dominantly with $\alpha$-Fe than that with $\beta$-Fe, indicating the lower susceptibility to hot-tearing for the former. 
- The liquid flow during the tensile deformation has a significant influence on the near-solid tensile properties, which is greatly affected by the morphology and distribution of the Fe-rich intermetallics. The liquid can be severely blocked by the interlocked $\beta$-Fe platelets, but it can flow more freely and feed the deformed region in the alloy with dominant $\alpha$-Fe, leading to its higher displacement to fracture.

\section{Acknowledgements}

The authors would like to acknowledge the financial support from the Natural Sciences and Engineering Research Council of Canada (NSERC) and Rio Tinto Aluminum, through the NSERC Industry Research Chair in Metallurgy of Aluminum Transformation at the University of Quebec at Chicoutimi and support of National Research Council of Canada.

\section{References}

[1] K. Liu, X. Cao, X.G. Chen (2011) Solidification of iron-rich intermetallic phases in Al-4.5Cu-0.3Fe cast alloy. Metall. Mater. Trans. A. 42 (7):2004-2016

[2] K. Liu, X. Cao, X.G. Chen (2012) Precipitation of iron-rich intermetallic phases in Al-4.6Cu-0.5Fe-0.5Mn cast alloy. J. Mater. Sci. 47 (10):4290-4298

[3] H. Kamguo Kamga, D. Larouche, M. Bournane, A. Rahem (2010) Solidification of aluminum-copper B206 alloys with ion and silicon additions. Metall. Mater. Trans. A. 41 (11):2844-2855

[4] B. Lin, R. Xu, H. Li, W. Zhang (2018) Formation of Fe-rich intermetallics in Al-5.0Cu-0.5 Fe alloys with different Mn additions. Materials Science and Technology. 34 (12):1447-1459

[5] S. Seifeddine, S. Johansson, I.L. Svensson (2008) The influence of cooling rate and manganese content on the $\beta$-Al5FeSi phase formation and mechanical properties of Al-Si-based alloys. Mater. Sci. Eng., A. 490 (1):385-390

[6] K. Liu, X. Cao, X.G. Chen (2012) Effect of Mn, Si, and cooling rate on the formation of iron-rich intermetallics in 206 Al-Cu cast alloys. Metall. Mater. Trans. B. 43 (5):1231-1240

[7] K. Liu, X. Cao, X.G. Chen (2013) Formation and phase selection of iron-rich intermetallics in Al-4.6Cu-0.5Fe cast alloys. Metall. Mater. Trans. A. 44 (2):682-695

[8] D.G. Eskin, Suyitno, L. Katgerman (2004) Mechanical properties in the semi-solid state and hot tearing of aluminium alloys. Prog. Mater. Sci. . 49 (5):629-711

[9] I. Farup, J.M. Drezet, M. Rappaz (2001) In situ observation of hot tearing formation in succinonitrile-acetone. Acta Mater. 49 (7):1261-1269

[10] H. Kamguo Kamga, D. Larouche, M. Bournane, A. Rahem (2010) Hot tearing of aluminum-copper B206 alloys with iron and silicon additions. Mater. Sci. Eng., A. 527 (27):7413-7423

[11] A. Bolouri, K. Liu, X.-G. Chen (2016) Effects of iron-rich intermetallics and grain structure on semisolid tensile properties of Al-Cu 206 cast alloys near solidus temperature. Metall. Mater. Trans. A. 47 (12):6466-6480

[12] A. Bolouri, X.-G. Chen (2017) Tensile deformation behavior of Al-Cu 206c ast alloys near the solidus temperature. Mater. Sci. Forum. 877 90-96

[13] L.J. Colley, M.A. Wells, D.M. Maijer (2004) Tensile properties of as-cast aluminum alloy AA5182 close to the solidus temperature. Mater. Sci. Eng., A. 386 (1):140-148 
[14] D. Fabrègue, A. Deschamps, M. Suery, J.M. Drezet (2006) Non-isothermal tensile tests during solidification of Al-Mg$\mathrm{Si}-\mathrm{Cu}$ alloys: Mechanical properties in relation to the phenomenon of hot tearing. Acta Mater. 54 (19):5209-5220

[15] A.B. Phillion, R.W. Hamilton, D. Fuloria, A.C.L. Leung, P. Rockett, T. Connolley, P.D. Lee (2011) In situ X-ray observation of semi-solid deformation and failure in Al-Cu alloys. Acta Mater. 59 (4):1436-1444 